\title{
ANALISIS HUBUNGAN POSTUR KERJA DENGAN KELUHAN MUSKULOSKELETALTERHADAP KINERJA KARYAWAN DI PT. BRI CAB PANAKKUKANG MAKASSAR TAHUN 2018
}

\author{
Astuti $\mathbf{R}^{1}$, Syamsiar S. Russeng ${ }^{2}$, Suharni A. Fachrin ${ }^{3}$ \\ 1 Universitas Muslim Indonesia \\ 2Universitas Muslim Indonesia \\ 3Universitas Muslim Indonesia
}

Alamat korespondensi : (Astutiners15@gmail.com/082390717373)

\begin{abstract}
ABSTRAK
Perbankan merupakan salah satu sektor yang berkembang pesat dan menunjang perekonomian.Negara secara keseluruhan. Saat ini kegiatan perbankan bekerja menggunakan komputer sebagai media kerja yang salah satu jenis pekerjaan beresiko dan akan berdampak buruk pada kesehatan seperti muskuloskeletal dan mengakibatkan kelelahan yang nantinya akan berdampak terhadap kinerja karyawan.Tujuan penelitian ini adalah untuk menganalisis hubunganposturkerja dengan keluhan muskuloskeletal terhadap kinerja karyawan PT. BRI di Kota Makassar.Jenis penelitian menggunakanobservasional analitik dengan pendekatan cross sectional. Teknik pengambilan sampling yaitu purposive sampling dengan jumlah sampel sebanyak 97 karyawan.Penelitian dilakukan di PT. BRI Cabang Panakukang Makassar. Hasil penelitian yang didapatkan ada hubungan postur kerja terhadap keluhan muskuloskeletal, ada hubungan antara postur kerja dengan kinerja, ada hubungan antara keluhan muskuloskeletal dengan kinerja karyawan di PT. BRI Cabang Panakukang Makassar.Kesimpulannya bahwa besarnya efek tidak langsung postur kerja terhadap kinerja melalui keluhan muskuloskeletal adalah -0,070 yang bermakna setiap peningkatan 1 poin beban kerja mampu menurunkan 0,070.Diharapkan dalam penelitian ini dapat memberikan tambahan informasi mengenai keluhan muskuloskeletal yang dialami oleh karyawan agar dijadikan pertimbangan dalam mengatasi masalahnya dan mengurangi keluhan muskuloskeletal agar kinerja karyawan dapat meningkat.
\end{abstract}

Kata kunci : postur kerja,keluhan muskuloskeletal, kinerja

\section{PENDAHULUAN}

Tenaga kerja mempunyai peranan penting dalam pembangunan sebangai unsur penunjang keberhasilan pembangunan nasional karena tenaga kerja mempunyai hubungan dengan perusahaan dan mempunyai kegiatan usaha yang produktif, disamping itu tenaga kerja sebagai suatu unsur yang langsung berhadapan dengan berbagai akibat dari kemajuan teknologi, sehingga sangat wajar jika mereka di berikan perlindungan pemeliharaan kesehatan dan pembangunan terhadap kesejahteraan pekerja.

Menurut ILO (International Labour Organization) tahun 2013, setiap tahun terjadi 2,3 juta kematian yang disebabkan oleh kecelakaan kerja dan penyakit akibat kerja. Data tersebut juga menyebutkan bahwa 2 juta kematian terjadi disebabkan oleh penyakit akibat kerja.Menurut Departemen Kesehatan RI tahun 2013, di Indonesia terdapat 428.844 kasus penyakit akibat kerja. Salah satu penyakit akibat kerja yang disebabkan oleh proses kerja yang tidak ergonomis adalah keluhan muskuloskeletal (Tarwaka, 2015).

Beban kerja sendiri merupakan kontributor penting untuk stres, tergantung dari tiap individu menghadapinya.French \& Caplan (1973) membedakan beban kerja menjadi; kuantitatif yang mengacu pada banyaknya pekerjaan yang harus dilakukan dan Kuanlitatif yang mengacu pada tingkat kesulitan suatu pekerjaan.Pada penelitian Shabbir \& Naqvi (2017) beban kerja dan kompleksitas kerja memiliki dampak positif dan signifikan terhadap stres kerja, sementara stres kerja memiliki dampak negatif pada kinerja pekerjaan.

Aktivitas bekerja menggunakan komputer dengan posis duduk merupakan salah satu jenis pekerjaan yang memiliki risiko menimbulkan rasa lelah pada bagian otot skeletal terutama bagian penyangga seperti tulang belakang, paha dan betis.Keluhan MSDs dikategorikan menjadi dua yaitu keluhan sementara dan keluhan menetap. (Hardianto dkk, 2015) 
Bekerja didepan komputer, saat dilihat secara keseluruhan, hampir seperti tidak memiliki pengorbanan yang besar dalam beraktivitas.Padahal pekerjaan dikantor juga dapat membawa dampak yang tidak baik bagi keselamatan \& kesehatan pegawai. Bahaya dan risiko yang dapat muncul akibat pekerjaan ini dikarenakan pegawai mengerjakan pekerjaan yang berulang-ulang dengan intensitas yang tinggi dengan postur yang sama atau pada postur yang tidak normal (awkward posture), sehingga dapat menimbulkan ketidaknyamanan dalam beberapa area tubuh. Selain itu juga, bahaya dan risiko dapat dikarenakan kurangnya pelatihan dan pemberitahuan kepada para pekerja mengenai faktor ergonomi dalam bekerja. Namun, ada pula pekerja yang telah mengetahui bahaya namun mengacuhkan hal tersebut karena belum ada dampak yang dirasakan.(Aisha, 2014)

Kapasitas kerja dari seorang tenaga kerja dapat dipengaruhi oleh beberapa faktor, salah satu faktor yang dapat berpengaruh dari segi gizi yaitu status gizi. Status gizi merupakan pengukuran dari sejauh mana terpenuhinya kebutuhan fisiologi individu akan zat gizi. Status gizi akan mencerminkan derajat pemenuhan kebutuhan fisiologi akan zat gizi. Status gizi merupakan hasil keseimbangan antara intake zat gizi dengan kebutuhan zat gizinya. (Dwinda listya., 2016)

$$
\text { Crassco dalam Tarwaka (2015) }
$$

menjelaskan bahwa posisi kerja duduk secara terus menerus dalam waktu yang lama dapat mengakibatkan keluhan otot berupa pegal, nyeri pada leher, bahu dan tulang belakang. Dan untuk mengetahui adanya keluhan digunakan kuesioner Nordic Body Map (NMB)

Besarnya beban kerja maupun kemampuan kerja yang diemban oleh para karyawan Bank Rakyat Indonesia akan berdampak juga pada kesehatan tubuh itu sendiri hingga hilangnya motivasi kerja. Dari hasil wawancara yang peneliti lakukan bahwa karyawan merasakan beban kerja yang tinggi dalam bekerja akan tetapi motivasi untuk menyelesaikan pekerjaan masih ada meskipun tidak terlalu besar karena ada beberapa faktor antara lain yaitu kebiasaan, niat, tanggung jawab dan kenikmatan dalam bekerja. Dampak yang dirasakan karyawan hanya beban kerja secara fisik saja.Namun, ini perlunya penataan dan tata kelola beban kerja harus sesuai dengan porsi dan kebutuhan karyawan serta harus disesuaikan dengan kemampuan kerja para karyawan itu sendiri. Beban kerja merupakan hal yang paling mendasar untuk mengetahui seberapa baik suatu perusahaan, atau seseorang karyawan melakukan suatu pekerjaan, yang pada akhirnya akan berpengaruh pada kinerja karyawan, atau perusahaan tersebut (Putra dan Achmad, 2012)

Perbankan merupakan salah satu sektor yang berkembang pesat dan menunjang perekonomian negara secara keseluruhan. Saat ini seluruh kegiatan perbankan bekerja menggunakan komputer sebagai media kerja merupakan salah satu jenis pekerja yang berisiko dan akan berdampak buruk pada kesehatannya seperti muskuloskeletal disorders dan mengakibatkan kelelahan. Karyawan mengalami kelelahan yang nantinya akan memengaruhi kinerja para karyawan itu sendiri, hal ini karena sikap kerja duduk didalam ruangan dalam waktu lama dan dilakukan secara monoton. Dimana jam kerja di bank itu mulai dari jam 08.00 sampai 16.00 Wita dan hanya memiliki waktu istrahat 1 jam yaitu jam 12.00 sampai jam 13.00 Wita. Dari hasil wawancara, di lingkungan bank ini tidak pernah diadakan soslialisasi tentang penyakit yang mungkin timbul akibat pekerjaan yang dilakukan. Sehingga peneliti ingin mengetahui lebih lanjut tentang seberapa besar HubunganPostur kerja dengan keluhan muskuloskeletal terhadap kinerja Karyawan PT. BRI di Kota Makassar

Tujuan penelitian ini adalah untuk menganalisis hubungan sikap kerja dengan keluhan muskuloskeletal terhadap kinerja karyawan PT. BRI di Kota Makassar?

\section{BAHAN DAN METODE}

Jenis penelitian yang digunakan adalah kuantitatif. Desain penelitian yang di gunakan adalah observasional analitik yaitu dimana peneliti hanya melakukan pengamatan saja atau melakukan pengukuran saja dan tidak melakukan intervensi dengan pendekatan cross sectional. Penelitian Cross Sectional adalah peneliti yang melihat hubungan antara variabel independen dan variabel dependen dengan cara mengamati keduanya secara serentak (diukur pada waktu yang sama). Penelitian ini akan melihat hubungan sikap kerja dengan keluhan muskuloskeletal disorders dan dampaknya terhadap kinerja karyawan.Penelitian ini menggunakan metode analisis jalur (path analysis) karena diantara variabel eksogen dan endogen terhadap terhadap variabel intervening.

Teknik pengumpulan data yang dilakukan dalam penelitian ini adalahEditing, Coding, Entry Data, Cleaning.Editing merupakan kegiatan yang dilakukan setelah kuesioner dikumpulkan kembali dari responden untuk melakukan pemeriksaan kelengkapan data, kejelasan dan konsistensi 
jawaban.Coding merupakan tahapan untuk pemberian kode pada setiap jawaban, kemudian diklasifikasikan dalam kelompokkelompok dengan kode yang sama.Setelah data lengkap dan diberi kode maka kemudian data diproses agar bisa dianalisis. Proses ini dilakukan dengan memasukkan data dari kuesioner ke dalam program computer SPSS Pada tahap ini setelah semua data darikuesioner di-entry, kemudian dicek kembali untuk mengetahui adanya kesalahan yang mungkin terjadi ketika proses meng-entry data dan selanjutnya dilakukan koreksi.

\section{HASIL PENELITIAN}

1. Hubungan postur kerja terhadap keluhan muskuloskeletal disorders

Tabel 1 Hubungan Postur Kerja Terhadap Keluhan Muskuloskeletal Terhadap Kinerja Karyawan PT. BRI Cab. Panakkukang Makassar Tahun 2018

\begin{tabular}{|c|c|c|c|c|c|c|c|c|}
\hline \multirow{2}{*}{$\begin{array}{c}\text { Postur } \\
\text { Kerja }\end{array}$} & \multicolumn{3}{|c|}{ Keluhan Muskuloskeletal } & \multirow{2}{*}{ Total } \\
\cline { 2 - 8 } & Ringan & Sedang & \multicolumn{2}{|c|}{ Berat } & \multicolumn{1}{c|}{} \\
\cline { 2 - 8 } & $\mathrm{n}$ & $\%$ & $\mathrm{n}$ & $\%$ & $\mathrm{n}$ & $\%$ & $\mathrm{n}$ & $\%$ \\
\hline Berat & 1 & 5.3 & 2 & 10.5 & 16 & 84.2 & 19 & 100.0 \\
\hline Sedang & 0 & 0.0 & 22 & 91.7 & 2 & 8.3 & 24 & 100.0 \\
\hline Ringan & 7 & 13.0 & 32 & 59.3 & 15 & 27.8 & 54 & 100.0 \\
\hline Total & 8 & 8.2 & 56 & 57.7 & 33 & 34.0 & 97 & 100.0 \\
\hline \multicolumn{10}{|c|}{$p$ value $=0.000$} \\
\hline
\end{tabular}

Berdasarkan Tabel 1 diperoleh data dari 97 responden dengan postur kerja berat dengan keluhan muskuloskeletal ringan sebanyak 1 responden (5.3\%) dan yang keluhan muskuloskeletal sedang sebanyak 2 responden (10.5\%), postur kerja berat dengan keluhan muskuloskeletal berat sebanyak 16 responden $(84.2 \%)$. Postur kerja sedang dengan keluhan muskuloskeletal ringan sebanyak 0 responden $(0.0 \%)$ dan yang keluhan muskuloskeletal sedang sebanyak 22 responden $(91.7 \%)$, dan postur kerja sedang dengan keluhan muskuloskeletal berat sebanyak 2 responden (8.3\%), sedangkan dengan beban kerja ringan keluhan muskuloskeletal yang ringan sebanyak 7 responden (13.0\%) dan yang keluhan muskuloskeletal sedang sebanyak 32 responden $(59.3 \%)$ sedangkan postur kerja ringan dengan keluhan muskuloskeletal berat sebanyak 15 responden $(27.8 \%)$. Dengan nilai $p$ value $=$ $0.000<0,05$ berarti adaHubungan postur kerja terhadap keluhan muskuloskeletal pada karyawan Bank BRI Cab. Panakkukang Makassar.

Dari hasil uji analisis path yang dilakukan pada variabel sikap kerja terhadap keluhan muskuloskeletal di peroleh hasil yakni dengan nilai estimate
0.371 dan nilai $p 0.000<0.05$ yang berarti bahwa variabel postur kerja berhubungan terhadap keluhan muskuloskeletal.Adapun carapengukuran postur kerja yaitu dengan Pengambilan data/ foto postur pekerja dengan menggunakan kamera. Untuk mendapatkan gambaran sikap (postur) pekerja dari leher, punggung, lengan, pergelangan tangan hingga kaki secara terperinci dilakukan dengan memotret postur tubuh responden. Hal ini dilakukan supaya peneliti mendapatkan data postur tubuh secara detail (valid), sehingga dari hasil foto bisa didapatkan data akurat untuk tahap perhitungan serta analisis selanjutnya. Perhitungan nilai melalui metode REBA ini dimulai dengan menganalisis posisi leher (neck), batang tubuh (trunk), dan kaki (legs) dengan memberikan score pada masing-masing komponen. Ketiga komponen tersebut kemudian dikombinasikan ke dalam sebuah tabel untuk mendapatkan nilai akhir pada bagian pertama atau score A dan ditambah dengan score untuk force atau load. Selanjutnya dilakukan scoring pada bagian lengan atas (upper arm), lengan bawah (lower arm), dan pergelangan tangan (wrist) kemudian ketiga komponen tersebut dikombinasikan untuk mendapatkan nilai akhir pada bagian kedua atau score B dan ditambah dengan coupling score. Setelah diperoleh grand score A dan grand score $\mathrm{B}$, kedua nilai tersebut dikombinasikan ke dalam tabel $\mathrm{C}$, melalui tabel kombinasi akhir ini kemudian ditambahkan dengan activity score akan didapat nilai akhir yang akan menggambarkan hasil analisis postur kerja. Dari skor REBA dapat diperoleh skala dari level tiap aksi yang akan memberikan panduan untuk resiko dari tiap level dan aksi yang dibutuhkan.

Berdasarkan hasil penelitian ini postur kerja berhubungandengan keluhan muskuloskeletal karena postur kerja duduk didepan komputer secara monoton dapat mengakibatkan keluhan muskuloskeletal disorders.

2. Pengaruh postur kerja terhadap kinerja Tabel 2. Hubungan Postur Kerja Dengan Kinerja KaryawanDi PT. BRI Cab. Panakkukang Makassar

\begin{tabular}{|c|c|c|c|c|c|c|c|c|}
\hline \multirow{2}{*}{$\begin{array}{c}\text { Postur } \\
\text { Kerja }\end{array}$} & \multicolumn{9}{|c|}{ Kinerja Karyawan } & \multicolumn{2}{c|}{ Total } \\
\cline { 2 - 9 } & Redah & \multicolumn{2}{c|}{ Cukup } & \multicolumn{1}{c|}{ Tinggi } & \\
\cline { 2 - 8 } & $\mathrm{n}$ & $\%$ & $\mathrm{n}$ & $\%$ & $\mathrm{n}$ & $\%$ & $\mathrm{n}$ & $\%$ \\
\hline Berat & 14 & 73.7 & 1 & 5.3 & 4 & 21.1 & 19 & 100.0 \\
\hline Sedang & 5 & 20.8 & 13 & 54.2 & 6 & 25.0 & 24 & 100.0 \\
\hline Ringan & 4 & 7.4 & 24 & 44.4 & 26 & 48.1 & 54 & 100.0 \\
\hline Total & 23 & 23.7 & 38 & 39.2 & 36 & 37.1 & 97 & 100.0 \\
\hline \multicolumn{8}{|c|}{$p$ value $=0.000$} \\
\hline
\end{tabular}


Berdasarkan Tabel 2 diperoleh data dari 97 responden dengan postur kerja berat dengan kinerja rendah sebanyak 14 responden $(73.7 \%)$ dan yang kinerja cukup sebanyak 1 responden (5.3\%), postur kerja berat dengan kinerja tinggi sebanyak 4 responden $(20.8 \%)$. Postur kerja sedang dengan kinerja rendah sebanyak 5 responden $(20.0 \%)$ dan yang kinerja cukup sebanyak 13 responden (54.2\%), dan postur kerja sedang dengan kinerja tinggi sebanyak 6 responden (25.0\%), sedangkan dengan postur kerja ringan dengan kinerja rendah sebanyak 4 responden $(7.4 \%)$ dan yang kinerja cukup sebanyak 24 responden (44.4\%) sedangkan postur kerja ringan dengan kinerja tinggi sebanyak 26 responden $(48.1 \%)$. Dengan nilai $p$ value $=0.000<$ 0,05 berarti adaHubungan postur kerja terhadap kinerja pada karyawan Bank BRI Cab. Panakkukang Makassar.

Dari hasil uji analisis path yang dilakukan pada variabel sikap kerja dengan kinerja di peroleh hasil yakni dengan nilai estimate -0.406 dan nilai $p 0.000<0.05$ yang berarti bahwa variabel sikap kerja berhubungan dengan kinerja karyawan.

Adapun carapengukuran sikap kerja yaitu dengan pengambilan data/foto postur pekerja dengan menggunakan kamera. Untuk mendapatkan gambaran sikap (postur) pekerja dari leher, punggung, lengan, pergelangan tangan hingga kaki secara terperinci dilakukan dengan memotret postur tubuh responden. Hal ini dilakukan supaya peneliti mendapatkan data postur tubuh secara detail (valid), sehingga dari hasil foto bisa didapatkan data akurat untuk tahap perhitungan serta analisis selanjutnya. Perhitungan nilai melalui metode REBA ini dimulai dengan menganalisis posisi leher (neck), batang tubuh (trunk), dan kaki (legs) dengan memberikan score pada masing-masing komponen. Ketiga komponen tersebut kemudian dikombinasikan ke dalam sebuah tabel untuk mendapatkan nilai akhir pada bagian pertama atau score A dan ditambah dengan score untuk force atau load. Selanjutnya dilakukan scoring pada bagian lengan atas (upper arm), lengan bawah (lower arm), dan pergelangan tangan (wrist) kemudian ketiga komponen tersebut dikombinasikan untuk mendapatkan nilai akhir pada bagian kedua atau score $B$ dan ditambah dengan coupling score. Setelah diperoleh grand score A dan grand score B, kedua nilai tersebut dikombinasikan ke dalam tabel $\mathrm{C}$, melalui tabel kombinasi akhir ini kemudian ditambahkan dengan activity score akan didapat nilai akhir yang akan menggambarkan hasil analisis postur kerja. Dari final REBA score dapat diperoleh skala dari level tiap aksi yang akan memberikan panduan untuk resiko dari tiap level dan aksi yang dibutuhkan.

Dalam penelitian ini dapat dilihat dari sikap kerja yang tidak alamiah, seperti sikap kerja duduk dan penggunaan desain kursi dalam bekerja, karena sikap badan yang tidak benar dalam melakukan pekerjaan dan lain-lain yang semuanya menimbulkan kelelahan fisik dan gangguan kesehatan sehingga sangat mempengaruhi kinerja karyawan.Sehingga pendekatan ergonomi menjadi penting dalam mengatasi permasalahan tersebut.Pembinaan SDM dengan pendekatan ergonomis perlu dilakukan agar karyawan tidak mengalami kekalahan dan gangguan kesehatan.Dengan demikian, pendekatan ergonomi merupakan pendekatan yang menyerasikan dan menyelaraskan tugas yang diberikan dengan kemampuannya sehingga mencapai kinerja yang maksimal.

\section{KESIMPULAN}

Kesimpulan yang dapat ditarik dari penelitian ini adalah Ada hubungan antara postur kerja dengan keluhan muskuloskeletal pada karyawan BRI cabang Panakkukang Makassar dengan nilai $p=0.000$ dengan kekuatan hubungan 0.371. Ada hubungan antara postur kerja dengan kinerja karyawan BRI cabang Panakkukang Makassar dengan nilai $p=0.000$ dengan kekuatan hubungan 0.406. Ada hubungan antara keluhan muskuloskeletal terhadap kinerja karyawan BRI cabang Panakkukang Makassar dengan nilai $p=0.139$ dengan kekuatan hubungan 0.190

\section{SARAN}

1. Karyawan pengguna komputer sebaiknya selalu menjaga kesegaran jasmani, relaksasi tubuh secara teratur, tidak menggunakan waktu istirahat berlebih untuk melanjutkan aktivitas kerja, melakukan olahraga rutin minimal 1 kali dalam seminggu dan tidak melakukan penambahan waktu kerja melebihi ketentuan yang ditentukan.

2. Perusahaan diharapkan untuk membuat suatu program kesehatan yang berbasis pekerja salah satunya adalah melakukan olahraga bersama satu kali dalam seminggu. 
3. Menetapkan lama kerja dalam sehari sesuai dengan ketentuan yang berlaku dan pembinaan SDM dengan pendekatan ergonomis perlu dilakukan agar karyawan tidak mengalami kekalahan dan gangguan kesehatan.

\section{DAFTAR PUSTAKA}

Dian Palupi R,dkk.2017. Metode REBA Untuk Pencegahan Musculoskeletal Disorder Tenaga Kerja. Jurnal Teknik Industri, Vol. 18, No. 01,

Fiqih Naila, dkk. 2017. Hubungan Indeks Massa Tubuh, Durasi Kerja dan Beban Kerja Fisik Terhadap Kebugaran Jasmani Karyawan Konstruksi Di PT. X.(http://ejournals1.undip.ac.id/index.php/jkm, diakses pada 4 September 2018)

Hardianto dkk, 2015. Faktor-Faktor Yang Berhubungan Dengan Keluhan Musculoskeletal Disorders (MSDs0 pada Karyawan Bank X. (diakses pada 4 September 2018)

Aisha, 2014.Office ergonomics assessment pada Kantor bank $\mathrm{x}$ (jrsi.sie.telkomuniversity.ac.id/index.php/JRSI/article/view/127, diakses pada 18 September 2018))

Nurjanah. 2012. Hubungan Sikap Kerja Duduk Dengan Muskuloskeletal pada pekerja Bagian Reaching di PT. Delta Merlin Dunia Karanganyar.(

Suma'mur. 2014. Higiene Perusahaan dan Kesehatan Kerja (HIPERKES). Jakarta: Sagung Seto.

Tarwaka.2015. Ergonomi Industri.Surakarta : Harapan Press. 